\title{
BUCKLING LOAD OF RC COLUMNS EXPOSED TO ISO FIRE LOAD The influence of the cross-sectional dimensions
}

\author{
Urška Bajc $^{\mathrm{a}}$, Miran Saje ${ }^{\mathrm{a}}$, Tomaž Hozjan ${ }^{\mathrm{a}}$, Igor Planinc ${ }^{\mathrm{a}}$, Sebastjan Bratina ${ }^{\mathrm{a}}$ \\ ${ }^{\text {a }}$ University of Ljubljana, Faculty of Civil and Geodetic Engineering, Ljubljana, Slovenia
}

\begin{abstract}
The influence of the cross-sectional dimensions on the buckling load capacity of reinforced concrete column exposed to ISO fire load is presented. The fire analysis is divided in two separate phases. In the first phase, the calculation of the temperatures over the cross-section of the concrete column is performed. Here more advanced hygro-thermal analysis is executed to take into account the influence of moisture on the distribution of the temperatures. In the second step of the fire analysis, the mechanical analysis is performed. The mechanical and thermal properties of concrete and reinforcement at elevated temperatures are used in accordance with EN 1992-1-2 (2004). For two different cross-sections, the parametric study has been performed. The critical buckling time and critical buckling capacity as a function of a load and slenderness of reinforced concrete column have been determined.
\end{abstract}

Keywords: RC column, fire, buckling, semi-analytical solution, cross-sectional dimensions

\section{INTRODUCTION}

The reinforced concrete (in the sequel RC) columns are the basic structural element of each frame as well as beams. Consequently, the behaviour of the columns substantially influence on the behaviour of the frames as a whole. Failure of the column may occur due to the material softening stocky columns, or due to phenomenon of buckling - slender columns. The deformability of the structure enlarges during fire and the RC frames are exposed to phenomena of buckling and stability problems even more. The aim of this paper is to show how the different cross-sectional dimensions influence load-carrying capacity of the column exposed to temperatures prescribed by ISO fire curve. Due to complexity of the present work, the fire analysis is divided in two separate phases. As input data for the first phase of fire analysis, the time distribution of a gas temperature in the fire compartment is assumed in accordance with standard EN 1991-1-2 (2004) by ISO fire curve. Next, a coupled hygro-thermal analysis in heterogeneous concrete is performed. In the second phase of the fire analysis, the mechanical analysis is accomplished where the critical buckling load and load-carrying capacity are determined. The main findings of short parametric study are gathered in the conclusions.

\section{NUMERICAL MODEL}

\subsection{Hygro-thermal analysis}

The transfer of temperatures, free water, and mixture of dry air and water vapour in concrete is obtained by the solution of the equations of a coupled heat and moisture transfer proposed by Davie et al. (Davie et al., 2006). The set of governing equations comprises the mass conservation of the three constituents - free water, water vapour and dry air, and an additional equation requiring the energy conservation to be satisfied:

$$
\begin{aligned}
& \frac{\partial\left(\varepsilon_{F W} \rho_{F W}\right)}{\partial t}=-\nabla \mathbf{J}_{F W}-\dot{E}_{F W}+\frac{\partial\left(\varepsilon_{D} \rho_{F W}\right)}{\partial t} \\
& \frac{\partial\left(\varepsilon_{G} \tilde{\rho}_{V}\right)}{\partial t}=-\nabla \mathbf{J}_{V}-\dot{E}_{F W}
\end{aligned}
$$




$$
\begin{aligned}
& \frac{\partial\left(\varepsilon_{G} \tilde{\rho}_{A}\right)}{\partial t}=-\nabla \mathbf{J}_{A} \\
& (\underline{\rho C}) \frac{\partial T}{\partial t}=-\nabla \cdot(-k \nabla T)-(\underline{\rho C \mathbf{v}}) \cdot \nabla T-\lambda_{E} \dot{E}_{F W}-\lambda_{D} \frac{\partial\left(\varepsilon_{D} \rho_{F W}\right)}{\partial t}
\end{aligned}
$$

In Eqs. (1)-(4) index $i$ denotes the phases of concrete, namely $i=F W$ is free water, $i=V$ is water vapour and $i=A$ is dry air. The unknown $\varepsilon_{i}$ is the volume fraction of a phase $i, \tilde{\rho_{i}}$ is the density of a phase $i$ for $\mathrm{m}^{3}$ of gaseous mixture, $\mathbf{J}_{i}$ is the mass flux of a phase $i$. $\dot{E}_{F W}$ is the specific heat of evaporation, $\varepsilon_{D}$ is the volume fraction of a chemically bound water in pores of concrete, $\rho_{F W}$ is the density of free water, $t$ means time. In Eq. (4) $\rho C$ denotes the heat capacity of concrete, $k$ is thermal conductivity, $\rho C \mathbf{v}$ relates to the energy transferred by fluid flow, $\lambda_{E}$ is the specific heat of evaporation, $\lambda_{D}$ is specific heat of dehydration and $T$ is the absolute temperature.

Making a sum of Eqs. (1) and (2) gives a system of three partial differential equations, which are solved numerically with Galerkin's type of finite element method. The primary unknowns are temperature, $T$, the pressure of gaseous mixture of water vapour and dry air, $P_{G}$, and the water vapour content, $\tilde{\rho}_{V}$. For in-deep description of the heat and moisture transfer in concrete and its numerical formulation, see Davie et al. (2006) and Kolšek et al. (2013).

\subsection{Mechanical analysis}

This chapter briefly describes the alternative procedure for the determination of the generalized Euler buckling loads with the help of the linearized system of equations for the material nonlinearity of the columns in fire. In stress-strain analysis of RC column the bending as well as membrane deformation are considered.

The procedure for determination of buckling load is as follows: $(i)$ we calculate the equilibrium state of the considered column which is modelled by the kinematically exact planar beam theory of Reissner (Reissner, 1972), consisting of kinematic, equilibrium and constitutive equations with the appropriate boundary conditions; (ii) by the help of the theory of stability (Keller, 1970), which assures that the buckling load is equal to the buckling load of the related linearized problem, with the solution obtained in point (i), we write a linear system of differential equations and solve it; (iii) we find the critical solution of the system present in point (ii), which already represents a buckling load of the RC column. Therefore, for determination of the generalized Euler buckling load of RC column we have to solve a system of two non-linear equations for two unknowns: the critical buckling load $P_{\text {cr }}$ and the critical axial deformation $\varepsilon_{0, \text { cr }}$. These two equations are:

$$
\begin{aligned}
& f_{1}^{i}\left(P_{\mathrm{cr}}, \varepsilon_{0, \mathrm{cr}}\right)=\left(1+\varepsilon_{0}\right) P_{\mathrm{cr}}-\frac{D \pi^{2}}{L_{\mathrm{u}}^{2}}=0, \\
& f_{2}^{i}\left(P_{\mathrm{cr}}, \varepsilon_{0, \mathrm{cr}}\right)=N_{\mathrm{c}}\left(\varepsilon_{0}, 0\right)-P_{\mathrm{cr}}=0 .
\end{aligned}
$$

In Eqs. (5) and (6), $N_{\mathrm{c}}$ is the constitutive axial force of the cross-section of the RC column and $D$ is the quantity that is closely related to the determinant of the current tangent constitutive matrix of the cross-section:

$$
D=C_{22}-C_{21} \frac{C_{12}}{C_{11}} \text {. }
$$

In Eq. (7), $C_{11}, C_{12}=C_{21}$ and $C_{22}$ are the components of the current tangent constitutive matrix of the cross-section and can be defined as: 


$$
C_{11}=\int_{A} \frac{\partial \sigma_{\mathrm{c}}}{\partial \varepsilon} \mathrm{d} A, \quad C_{12}=C_{21}=\int_{A} z \frac{\partial \sigma_{\mathrm{c}}}{\partial \varepsilon} \mathrm{d} A, \quad C_{22}=\int_{A} z^{2} \frac{\partial \sigma_{\mathrm{c}}}{\partial \varepsilon} \mathrm{d} A
$$

Eqs. (5) and (6) cannot be solved analytically and the solution needs to be obtained numerically. As the problem is governed by fully non-linear equations, and only Eqs. (5) and (6) need to be solved numerically, we name this kind of formulaton 'semi-analytical'. The semi-analytical procedure is, in principle, the same for any end conditions (Krauberger, 2007), the only changeable parameter at the constant cross-section of the RC column during fire being the buckling length $L_{\mathrm{u}}$. Therefore, Eqs. (5) and (6) are solved in an incremental way, incrementing either the time or the mechanical load depending on whether the critical time or the critical load is sought. The time of fire analysis is divided into small time intervals $\left[t_{i-1}, t_{i}\right]$ and the stress-strain state at each time $t_{i}$ is then determined iteratively. For in-deep description of mechanical analysis, see the work of Bajc et al. (2014).

By changing the temperature of RC column, the mechanical and thermal properties of concrete and reinforcing bars may rapidly change as well, and their dependence on temperature should not be neglected. Here it is neccessary to consider the principle of additivity of strains. We assume that the total strain increment of concrete, $\Delta \varepsilon_{\mathrm{c}}$, is the sum of the strain increments due to temperature, $\Delta \varepsilon_{\mathrm{th}, \mathrm{c}}$, stress, $\Delta \varepsilon_{\sigma, \mathrm{c}}$, creep, $\Delta \varepsilon_{\mathrm{cr}, \mathrm{c}}$, and transient, $\Delta \varepsilon_{\mathrm{tr}, \mathrm{c}}$, strain. The total strain increment of reinforcement, $\Delta \varepsilon_{\mathrm{s}}$, is the sum of the strain increments due to temperature, $\Delta \varepsilon_{\mathrm{th}, \mathrm{s}}$, stress, $\Delta \varepsilon_{\sigma, \mathrm{s}}$, and steel creep, $\Delta \varepsilon_{\mathrm{cr}, \mathrm{c}}$, strain. The detail description of strain increments is presented in the work of Bratina et al. (2007).

\section{NUMERICAL EXAMPLE}

In the numerical example to follow, we analyse the influence of the cross-sectional dimensions on buckling of a RC column. In present short parametric study the critical buckling time and the critical buckling load at a chosen time of the fire spread as functions of the load and the slenderness of the RC column have been determined. The geometric, material and loading data of simply supported RC column are shown in Fig. 1.

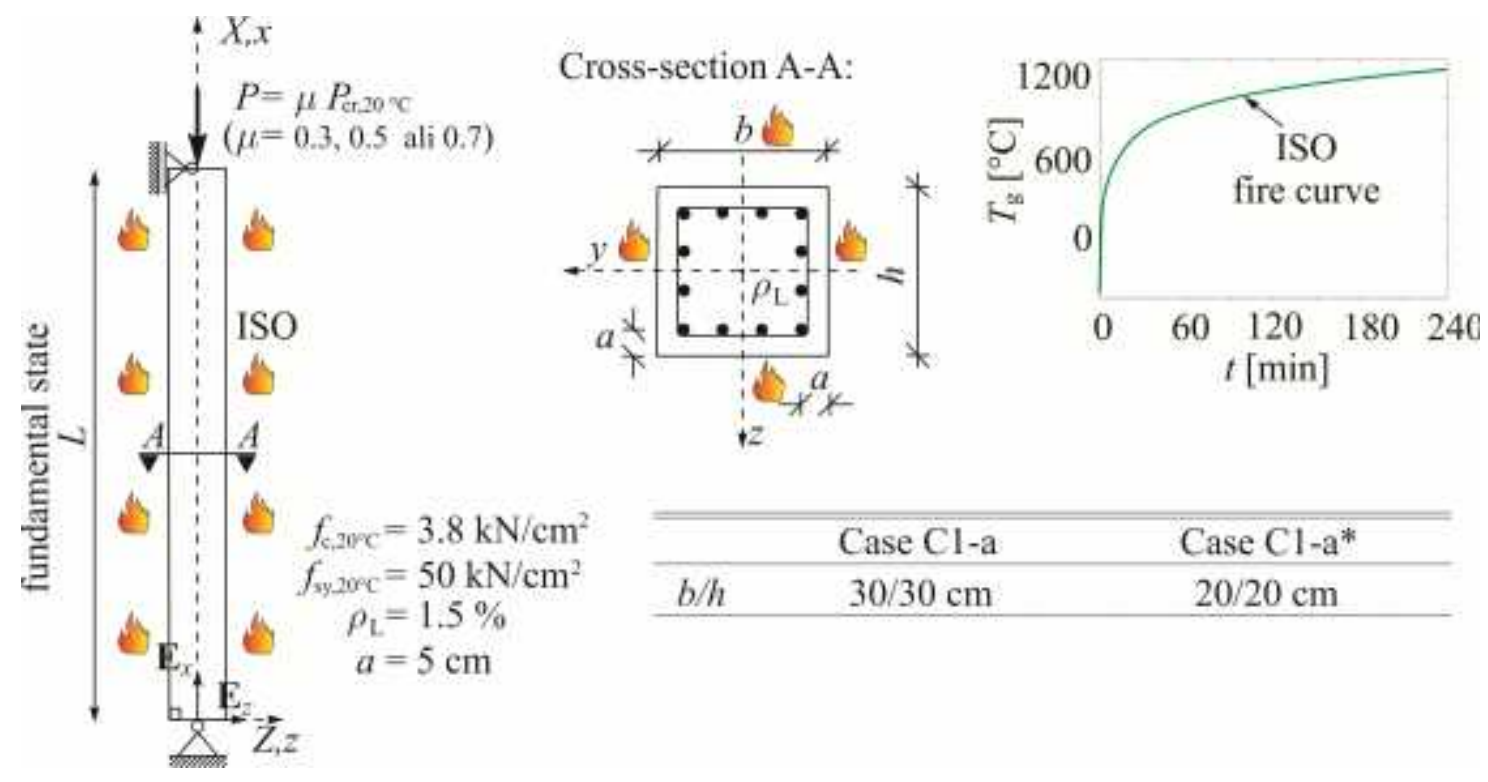

Fig. 1 A simply supported RC column. The geometrical, material and loading data. 
The RC column with length $L$, which is subjected to initial compressive load of different magnitudes, $P=\mu P_{\mathrm{cr}, 20^{\circ} \mathrm{C}}(\mu=0.3,0.5,0.7)$, and to ISO fire load, is considered. Here, $P_{\mathrm{cr}, 20^{\circ} \mathrm{C}}$ denotes the critical buckling load of the identical RC column at room temperature $T=20{ }^{\circ} \mathrm{C}$. We consider the concrete column with a quadratic cross-sectonal dimensions of $b / h=30 / 30 \mathrm{~cm}$ (Case $\mathrm{C} 1-\mathrm{a})$ and $b / h=20 / 20 \mathrm{~cm}$ (Case $\left.\mathrm{C} 1-\mathrm{a}^{*}\right)$. The column is reinforced with 12 reinforcing bars in both cases, and the reinforcement ratio is taken to be $\rho_{\mathrm{L}}=1.5 \%$. The distance between the reinforcing bar and the nearest concrete surface is $a$, which is taken to be $5 \mathrm{~cm}$. The material parameters of concrete and reinforcing steel at the room temperature remain unchanged in the parametric study and are selected as: compressive strength of concrete $f_{\mathrm{c}, 20^{\circ} \mathrm{C}}=3.8 \mathrm{kN} / \mathrm{cm}^{2}$, tensile strength of steel $f_{\mathrm{sy}, 20^{\circ} \mathrm{C}}=50 \mathrm{kN} / \mathrm{cm}^{2}$, and elastic modulus of steel $E_{\mathrm{c}}=20000 \mathrm{kN} / \mathrm{cm}^{2}$. The remaining material parameters needed for the description of constitutive laws are taken in accordance with EN 1992-11 (2004) and EN 1992-1-2 (2004).

\subsection{The determination of the temperature field}

The RC column is on all four sides exposed to fire. The temperature of the gases in the fire compartment varies with time according to the ISO fire curve (see Fig. 1). We assume that the gas temperature around the column is constant. Consequently, the variations of temperature over the typical cross-section of the RC column during fire with time remain unchanged in the $x$-direction. The solution of the system of partial differential equations is obtained with the finite element method as described in Sec. 2.1. Due to symmetry of the cross-section, only one quarter is considered and a regular mesh of $900(\mathrm{C} 1-\mathrm{a})$ and $400\left(\mathrm{C} 1-\mathrm{a}^{*}\right)$ four-node finite element, respectively, are used. The time interval $t=0.5 \mathrm{~s}$ is chosen in the time integration (Hozjan, 2011). The remaining material parameters used in hygro-thermal analysis are taken in accordance with the paper of Davie et al. (2006). Fig. 2(a) and (b) shows the distributions of the temperature over the cross-section $\mathrm{C} 1-\mathrm{a}(\mathrm{b} / \mathrm{h}=30 / 30 \mathrm{~cm})$ and $\mathrm{C} 1-\mathrm{a}^{*}(b / h=20 / 20 \mathrm{~cm})$, respectively, of the column for the different time of fire exposure. As expected, the temperatures in centre of cross-section are higher for reduced concrete-section.

(a) C1-a
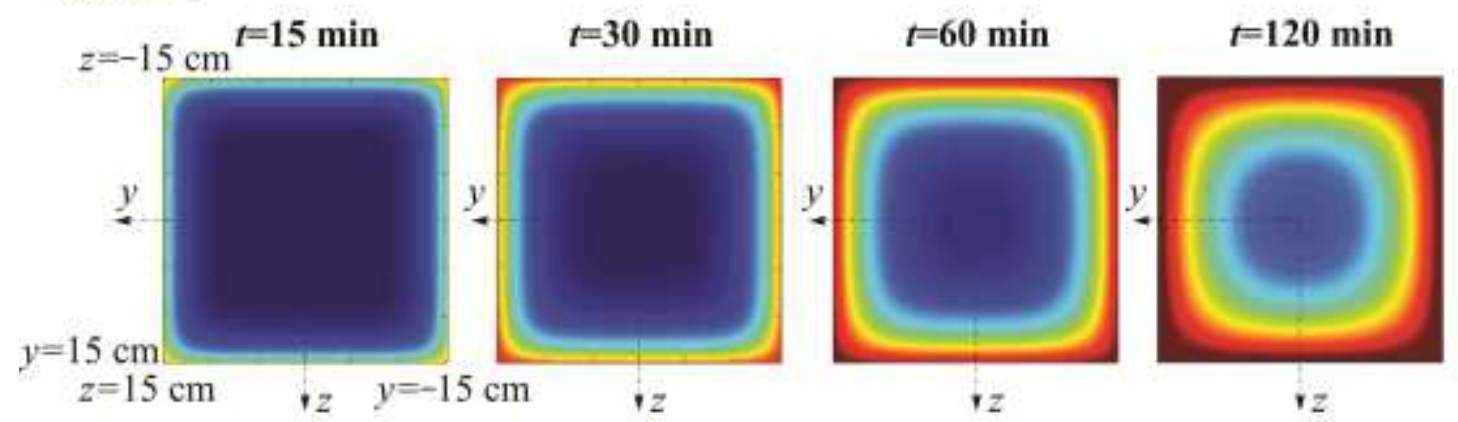

(b) $\mathrm{C} 1-\mathrm{a}^{*}$
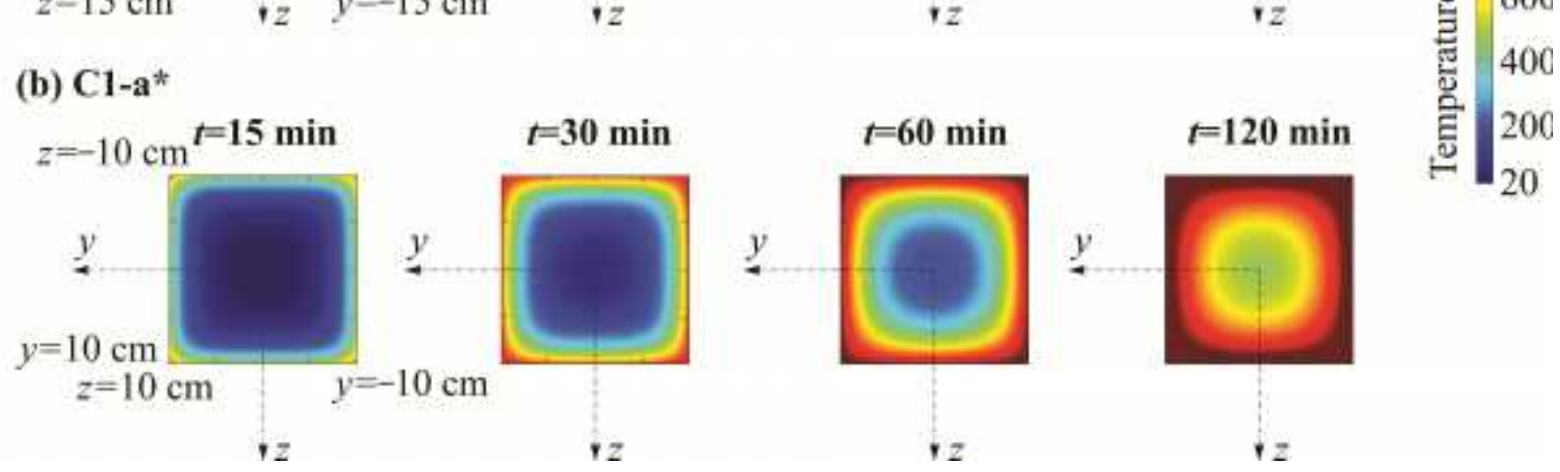

Fig. 2 Temperature field for different cross-sectional dimensions at 15, 30, 60 and 120 min of fire exposure for (a) $\mathrm{C} 1-\mathrm{a}$ and (b) $\mathrm{C} 1-\mathrm{a}^{*}$ 


\subsection{Mechanical analysis}

The analysis is carried out for three different initial mechanical load magnitudes $\mu=0.3,0.5,0.7$ and the ISO fire load. The results are presented in Fig. 3(a). The columns with the smaller cross-section, $b / h=20 / 20 \mathrm{~cm}$ (C1-a*), have approximately $60 \%$ smaller load carrying-capacity at room temperature, $P_{\mathrm{cr}, 20^{\circ} \mathrm{C}}$, when compared to the same slender columns with the cross-section $b / h=30 / 30 \mathrm{~cm}(\mathrm{C} 1-\mathrm{a})$. Therefore, the mechanical load $P$ is reduced in the same way. On the other hand, the critical time of the columns $\mathrm{C} 1-\mathrm{a}^{*}$ in fire is reduced only for about $20 \%$ to $40 \%$ when compared to columns with the same slenderness and the cross-section C1-a (Fig. 3(a)).

(a) Critical buckling time $t_{\mathrm{cr}}$

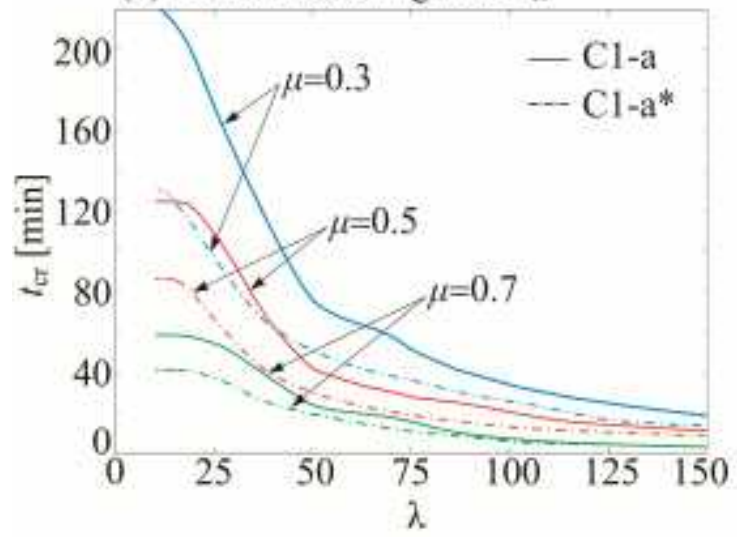

(c) Critical buckling load, $\mu=0.5$

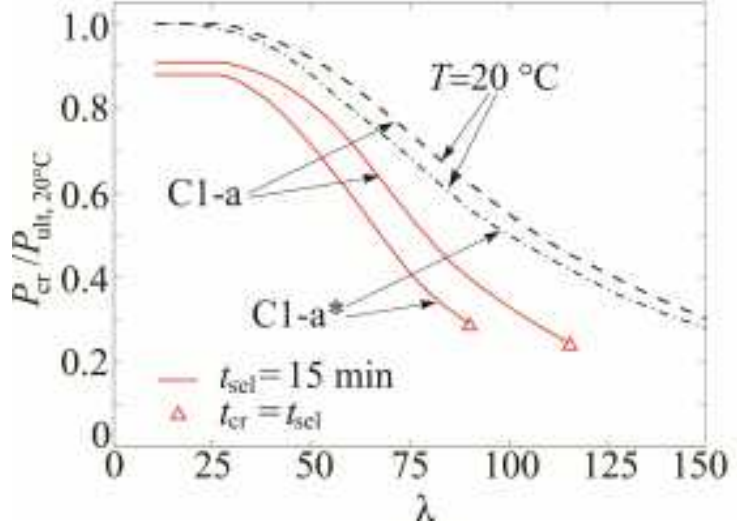

(b) Critical buckling load, $\mu=0.3$

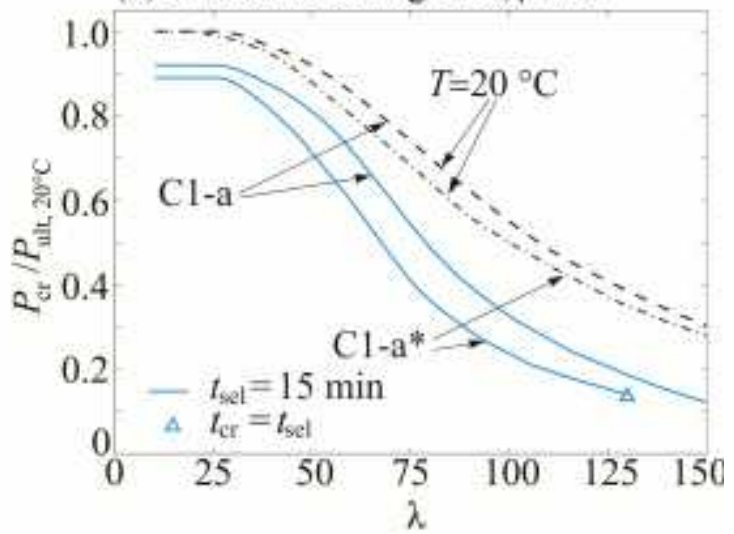

(d) Critical buckling load, $\mu=0.7$

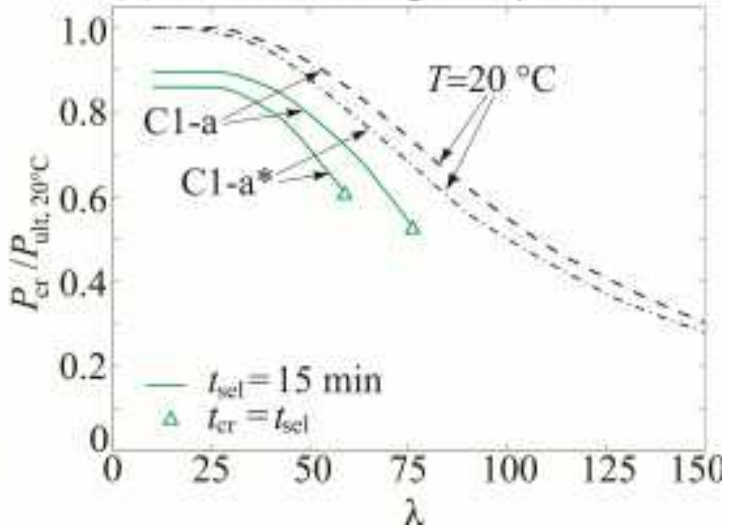

Fig. 3 The influence of the cross-sectional dimensions and different initial magnitudes of the load on critical buckling time and critical buckling load: (a) critical time $t_{\mathrm{cr}}$; (b) critical buckling load for $\mu=0.3$; (c) $\mu=0.5$ and (d) $\mu=0.7$.

We have also analysed the influence of the cross-section dimensions on the remaining load carrying capacity of the column, $P$, previously exposed to $15 \mathrm{~min}$ fire, for three different initial load levels. We compare the behaviour of columns $\mathrm{C} 1-\mathrm{a}$ and $\mathrm{C} 1-\mathrm{a}^{*}$. The results are presented in Figs. 3(b), (c), (d). Here all graphs have been normalized by the load-carrying capacities of the individual crosssections $\mathrm{C} 1-\mathrm{a}$ and $\mathrm{C} 1-\mathrm{a}^{*}$ at room temperature, $P_{\mathrm{cr}, 20^{\circ} \mathrm{C}}=4042.8 \mathrm{kN}$ and $P_{\mathrm{cr}, 20^{\circ} \mathrm{C}}=1806.3 \mathrm{kN}$, respectively. The critical loads are presented only for the columns whose critical time is higher than selected time $t_{\mathrm{sel}}=15 \mathrm{~min}$. The results demonstrate that the initial magnitude of the mechanical load, $P$, has a small effect on the load-carrying capacity of column in a short fire. After 15 min of the fire duration, short columns $(\lambda<20)$ with cross-sections $\mathrm{C} 1-\mathrm{a}$ and $\mathrm{C} 1-\mathrm{a}^{*}$, still keep about $90 \%$ of the load-carrying capacity of the cross-section at room-temperature at the same slendernesses. The effect of fire on the load-carrying capacity of slender columns $(\lambda \sim 76)$ is, however, more pronounced, and amounts to $52 \%$ and $43 \%$, respectively. 


\section{CONCLUSIONS}

The paper presents the influence of the cross-sectional dimensions on the buckling load capacity of RC column exposed to temperatures prescribed by ISO fire curve (EN 1991-1-2, 2004). The results, i.e. the critical buckling time and the critical buckling capacity, are presented for different magnitudes of the load and various column slendernesses where the reinforcement ratio remains unchanged as well as the number of reinforcing bars. In accordance with present analysis, we use the temperature dependent constitutive laws of concrete and reinforcing bars as suggested in EN 1992-1-2 (2004). By the short parametric study we find out that the columns with smaller crosssectional dimensions experience a larger reduction of their load carrying-capacity at room temperature in comparison to the same slender columns with larger initial cross-sectional dimensions, but the reduction of the critical time during fire is smaller. The analysis of the remaining load-carrying capacity of the columns previously exposed to short fire shows that the smaller cross-sectional dimensions of comparable slender columns have a small influence on the reduction of their load-carrying capacity, irrespective to the magnitude of the initial load.

\section{ACKNOWLEDGMENTS}

The work of U. Bajc was partly financially supported by the Slovenian Research Agency under Contract no. 1000-10-310088. The support is gratefully acknowledged.

\section{REFERENCES}

Bajc, U., Saje, M., Planinc, I., Bratina, S. 2014. Semi-analytical buckling analysi of reinforced concrete columns exposed to fire, Fire Safety Journal 71, p. 110-122.

Bratina, S., Saje, M., Planinc, I. 2007. The effects of different strain contributions on the response of RC beams in fire, Engineering Structures, 29, p. 418-430.

Davie, C.T., Pearce, C.J., Bićanić, N. 2006. Coupled heat and moisture transport in concrete at elevated temperatures - Effects of capillary pressure and adsorbed water. Numerical Heat Transfer, Part $\quad A$ : Applications 49:733-763, 2006.

Eurocode 1 2004. Action structures - Part 1-2: General actions - actions on structures exposed to fire EN 1991-1-2:2004.

Eurocode 2 2004. Design of concrete structures - Part 1-1: General rules and rules for buildings EN 19921-1:2004.

Eurocode 2 2004. Design of concrete structures - Part 1-2: Structural fire design EN 1992-1-2:2004.

Kolšek, J., Planinc, I., Saje, M., Hozjan, T. 2013. The fire analysis of a steel-concrete side-plated beam. Finite Elements in Analysis and Design, 74, p. 93-110.

Hozjan, T., Saje, M., Srpčič, S., Planinc, I. 2011. Fire analysis of steel-concrete composite beam with interlayer slip, Computers and Structures, 89, p. 189-200.

Keller, H.B. 1970. Nonlinear bifurcation, Journal of Differential Equations, 7, p. 417-434.

Krauberger, N., Saje, M., Planinc, I., Bratina, S. 2007. Exact buckling load of a restrained RC colimn, Strustal Engineering and Mechanics, 27, p. 293-310.

Reissner, E. 1972. On one-dimensional finite-strain beam theory: The plane problem. Journal of Applied Mathematics and Physics (ZAMP), 23, p. 795-804. 